\title{
Controlled biopolymer roughness induced by plasma and excimer laser treatment
}

\author{
P. Slepička*, I. Michaljaničová, V. Švorčík \\ Department of Solid State Engineering, Institute of Chemical Technology, 16628 Prague, Czech Republic
}

Received 23 May 2013; accepted in revised form 4 August 2013

\begin{abstract}
A new method for biopolymer poly-L-lactic-acid (PLLA) surface nanostructuring with surface plasmon resonance appearance is proposed. The motivation of this work is to determine optimal conditions for rough or flat biopolymer surface which may find broad application in tissue engineering as biocompatible carrier for various types of cell lines. A combination of plasma pre-treatment with consequent excimer laser exposure is proposed as a method for increasing the roughness of PLLA surface and changing its morphology. The focus of this paper is to determine morphology changes in combination with mass loss changes. The ablation loss and morphology of PLLA was induced by excimer laser exposure of plasma pre-treated PLLA with different laser fluencies and number of pulses. The combination of a certain input parameters of plasma pre-treatment together with laser exposure induces extensive physico-chemical changes (morphology, contact angle, optical properties) on polymer surface with dramatic roughness increase. Gravimetric studies have revealed an extensive polymer ablation after excimer laser application. The effect of surface plasmon resonance was observed in laser modified PLLA. Conditions for PLLA surface flattening are also proposed.
\end{abstract}

Keywords: nanomaterials, biodegradable polymers, plasma pre-treatment, excimer laser, surface characterization

\section{Introduction}

Synthetic biodegradable polymers are the most versatile of all materials used in tissue engineering [1, 2]. Their surface properties can be changed e.g. by the application of plasma discharge or laser treatment [3] or by grafting procedures and the limitations of the scaffold architecture could be improved. Poly-L-lactic-acid is such kind of polymer that has been extensively used in tissue engineering [4]. Biodegradable polymers $[5,6]$ are promising scaffolding materials; however, the roughness of polymer and its surface structure may play a significant role in cell-polymer interaction with a significant improvement of biocompatibility [7]. The surface of a solid material is important to the material performance $[8,9]$ in at least two aspects, (i) the microstruc- ture and (ii) properties of surfaces, which are usually different from those in the bulk.

Although PLLA polymer represents an important member of biodegradable polymers family, only a few papers have been published about the biomaterial interaction with an excimer laser. The effect of excimer laser exposure on crystallinity and chemical changes of biodegradable polymer has been recently published [3]. The surface modification of biopolymer by ArF laser has been studied [10]. The effect of $\mathrm{KrF}$ excimer laser treatment on surface properties of biopolymer foils in combination with plasma treatment remains still to be discovered.

This paper deals with the surface modification of PLLA by plasma pre-treatment in combination with consequent exposure by excimer laser. The effect of

\footnotetext{
${ }^{*}$ Corresponding author, e-mail: petr.slepicka@vscht.cz

(C) BME-PT
} 
these modifications on its surface morphology is introduced. The ablation (mass loss) of plasma pretreated samples by excimer laser exposure is determined. The effect of laser pulses number and laser fluence is investigated. The roughness and surface morphology of PLLA was studied by AFM, ablation by gravimetry and surface plasmon resonance by UV-Vis spectroscopy, contact angle measurement by goniometry. The surface induced changes represented by the alteration of both surface morphology and roughness are described in detail. The proposed technique of combination of plasma treatment and excimer modification has been successfully applied for ‘super-rough' biopolymer surface.

\section{Materials and methods}

\subsection{Materials, plasma pre-treatment, laser exposure}

We used biopolymer poly(lactic acid) (PLLA, density $1.25 \mathrm{~g} \cdot \mathrm{cm}^{-3}, T_{\mathrm{g}}=60^{\circ} \mathrm{C}$, crystallinity $60-70 \%$, $50 \mu \mathrm{m}$ thick foils, supplied by Goodfellow Cambridge Ltd., Cambridge, Great Britain).

Plasma treatment was accomplished with diode plasma discharge on Balzers SCD 050 (BalTec Maschinenbau AG, Pfäffikon, Switzerland), device for $240 \mathrm{~s}$, using DC Ar plasma (gas purity was 99.997\%, $10 \mathrm{~W})$. Process parameters were: Ar flow $0.3 \mathrm{~L} \cdot \mathrm{s}^{-1}$, Ar pressure $10 \mathrm{~Pa}$, electrode area $48 \mathrm{~cm}^{2}$, the inter-electrode distance of $50 \mathrm{~mm}$, chamber volume $1000 \mathrm{~cm}^{3}$.

For exposure of the PLLA we employed an $\mathrm{KrF}$ excimer laser (Coherent Compex Pro 50, Santa Clara, CA USA, wavelength of $248 \mathrm{~nm}$, pulse duration of 20-40 ns, repetition rate $10 \mathrm{~Hz}$ ). The beam of $\mathrm{KrF}$ laser was polarized linearly with cube of UV grade fused silica $25 \times 25 \times 25 \mathrm{~mm}$ with active polarization layer. For homogeneous illumination of the samples we used only the central part of the beam profile by means of an aperture $\left(0.5 \times 1 \mathrm{~cm}^{2}\right)$. The samples were mounted onto a translation stage at perpendicular position of the sample and laser beam. The pulses were chosen from 500 to 6000 with laser fluencies in the interval of $6-30 \mathrm{~mJ} \cdot \mathrm{cm}^{-2}$. All experiments with laser treatment of biopolymer PLLA were performed on the samples firstly pre-treated with argon plasma (power $10 \mathrm{~W}$ and exposure time $240 \mathrm{~s}$ ) and consecutively aged for 72 hours, when the surface is 'aged' and stabilized with the exception of samples for comparison.

\subsection{Measurement techniques}

Surface morphology and roughness of the pristine, plasma and laser treated PLLA samples was examined by AFM technique using a Bruker Corporation CP-II setup (Santa Barbara, CA, USA) device in tapping mode. A Si probe RTESPA-CP with the spring constant of $20-80 \mathrm{~N} \cdot \mathrm{m}^{-1}$ was used. The mean roughness value $\left(R_{\mathrm{a}}\right)$ represents the arithmetic average of the deviations from the centre plane of the sample. Mean thickness of the removed surface layer after the plasma ablation was measured using a Mettler Toledo UMX2 (Metler Toledo LLC, Columbus, USA) microbalance. The thickness of the removed layer was calculated from the measured change of weight of 3 samples before and after the treatment. The depolarization high-frequency gate was used to discharge the sample surface in order to minimize the influence of surface electrostatic charge on the measurement. After weight-loss determination the ablated thickness was calculated (error $\pm 5 \%$ ) from the weight of the ablated layer, area of the sample and the PLLA density.

The UV/Vis spectra were measured using a Perkin Elmer Lambda 25 spectrometer in the spectral range from 225 to $400 \mathrm{~nm}$. Applicable range is 190 $1100 \mathrm{~nm}$ with bandwidth $1 \mathrm{~nm}$ (fixed).

Contact angle was determined by goniometry using static water drop method. The measurements of the water contact angles (error $\pm 5 \%$ ) were performed using distilled water on 4 different positions using the Surface Energy Evaluation System (SEE System, Advex Instruments, Czech Republic). By automatic pipette a water droplet of volume $(8.0 \pm 0.2) \mu \mathrm{L}$ was deposited on the polymer's surface and the consequent photo was evaluated. The set of values were then evaluated with the Origin 8.0 program.

\section{Results and discussion}

\subsection{Plasma pre-treatment}

The first step of PLLA surface modification was the pre-treatment of the polymer surface by Ar plasma discharge. Previous experiments with only laser exposure of PLLA did not reveal ripple-like patterning of biopolymer PLLA or its significant roughness increase $[12,13]$. Therefore the plasma pre-treatment has been implemented. Since the goal of our study was to prepare a highly rough polymer surface, the modification ( $10 \mathrm{~W}$ and $240 \mathrm{~s}$ ) was chosen for the consequent experiments since the most pronounced 



Figure 1. Surface morphology and roughness of pristine PLLA and PLLA pre-treated in argon plasma with $10 \mathrm{~W}$ and $240 \mathrm{~s}$

changes in morphology were observed with higher plasma power [14]. As it is obvious from Figure 1, plasma pre-treatment leads to a mild increase of the surface roughness of PLLA. The pristine PLLA sample exhibits lower surface roughness in comparison with the treated samples and 'pits' are apparent on the modified surface. During plasma pre-treatment, the ablation of the polymer surface takes place [14]. The different ablation rate of crystalline and amorphous phases results in the appearance of crystalline structures on the treated PLLA surface. The frequency of crystallites being more pronounced on the treated PLLA with higher plasma power. The amplification of the crystalline phase on the PLLA surface leads to an increase of surface roughness [14]. It is known that beam treatment (e.g. plasma, ions, laser, excimer lamp) of polymer leads to the cleavage of chemical bonds (e.g. C-H, $\mathrm{C}-\mathrm{C}, \mathrm{C}-\mathrm{O})[15,16]$. It was shown previously that carbonyl, carboxyl and ester groups are created on the polymer surface layers by the oxidation during or after plasma treatment [17]. The re-orientation of surface polar groups on the polymeric chain leads to lower oxygen concentration in comparison to theoretical value thus influencing the wettability [18].

\subsection{Polymer laser ablation}

We investigated the influence of laser exposure of plasma pre-treated PLLA (by different number of pulses and laser fluence) on its thickness loss. Since the laser exposure can cause thickness loss of exposed foil, it is important to study the ablation of modified PLLA foil. The thickness loss of PLLA foil induced by plasma pre-treatment under similar

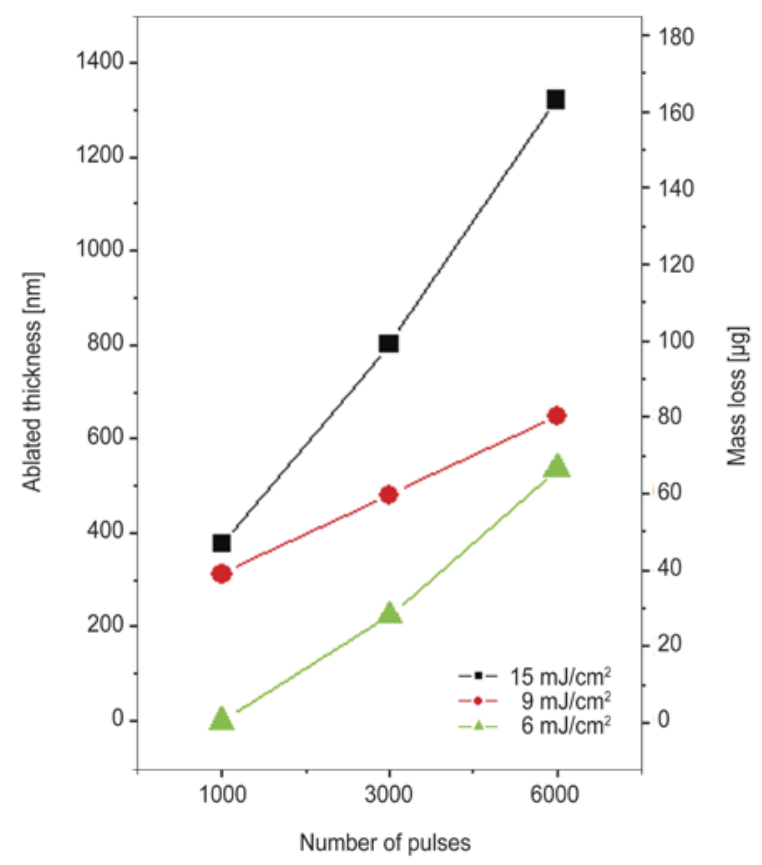

Figure 2. The dependence of PLLA ablated thickness and mass loss on number of laser pulses for laser fluence $6-15 \mathrm{~mJ} \cdot \mathrm{cm}^{-2}$. PLLA samples have been pre-treated with plasma $(10 \mathrm{~W}, 240 \mathrm{~s})$

conditions did not exceeded $100 \mathrm{~nm}$ [14]. If the thickness loss caused by consequent laser exposure would be too high, the PLLA surface alteration would not be effective as the mechanical properties of modified foil could be lost. The thickness loss and ablation of plasma pre-treated polymer foils was studied for consequent laser exposure with pulses from 1000 up to 6000 (Figure 2). This number of pulses was applied with laser fluences from 6, 9 and $15 \mathrm{~mJ} \cdot \mathrm{cm}^{-2}$. It was found, as expected, that the thickness loss of PLLA foil significantly increases both with increasing laser fluence and number of 
laser pulses. With increasing laser fluence the effect of laser pulses becomes stronger. However, the value of thickness loss did not exceeded $1.5 \mu \mathrm{m}$ (15 mJ and 6000 pulses) which represents about 3\% of the bulk. Another important result is that the plasma pre-treatment causes significantly lower ablation in comparison to the excimer laser. Plasma exposure leads to the preferential ablation of the amorphous phase which results in the appearance of the crystalline structures on the treated polymer surface. The heavy argon ions impacting the polymer surface cause polymer bond breakage until the macromolecular chains are released to the ambient atmosphere. The laser exposure (photon impacts) influences also the crystalline phase of the polymer. By the absorption of ultraviolet light also the thermal bond breakage takes place probably, when an inhomogeneous heat flux is present on the biopolymer surface between the pulses [8].

\subsection{Surface contact angle (wettability)}

The dependence of PLLA contact angle on laser fluence is introduced in Figure 3. The samples were used pre-treated with plasma and aged for more than 72 hours, that means that the input values of PLLA contact angle before laser exposure were those of $90^{\circ}$ (surface is stabilized). As it can be concluded from Figure 3, laser exposure leads to the decrease contact angle by aged PLLA and even from pristine PLLA (it is cca $71^{\circ}$ ). This decrease depends on the number of laser pulses and laser fluence. The

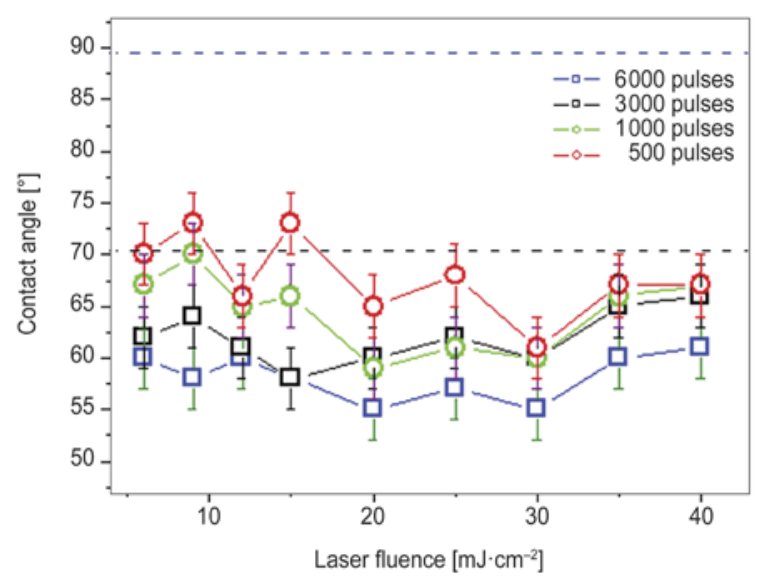

Figure 3. The dependence of contact angle of plasma pretreated PLLA surface on laser fluencies with different laser number of pulses (500-6000). Black dash line represents contact angle for pristine PLLA, blue dash line (upper one) represents contact angle of aged plasma pre-treated $(10 \mathrm{~W}$, 240 s) PLLA. sample treated with 500 pulses exhibits the highest values of contact angle in comparison to samples exposed with higher number of pulses. With increasing laser fluence the surface morphology is strongly influenced. With more pronounced ablation also the surface chemistry is significantly altered. The macromolecular chains rearrangement ability and chemical structure of modified surface is influenced by the laser fluence. The changes of contact angle are probably caused by several factors involving surface roughness change, e.g. the stability of treated surface (ability to macromolecular chains rearrangement) and amount of ablated biopolymer material. The slight fluctuations of contact angle appear, probably due to the ablation of polymer surface, which were confirmed earlier (Figure 2). The most pronounced decrease of contact angle was observed for samples treated for 6000 pulses. However, the slight increase with higher laser fluence $\left(40 \mathrm{~mJ} \cdot \mathrm{cm}^{-2}\right)$ was observed, probably due to more pronounced ablation. The trend of contact angle decrease with higher laser fluence on pristine PLLA was also observed [10], however the PLLA and type of excimer laser was different from our experimental set-up.

\subsection{Preparation of highly rough surface}

The surface morphology for selected laser exposed samples (fluence $9 \mathrm{~mJ} \cdot \mathrm{cm}^{-2}$ ) is introduced in Figure 4. This laser fluence was chosen since the modification in the interval of $9-15 \mathrm{~mJ} \cdot \mathrm{cm}^{-2}$ led to the roughness increase similar to that of $9 \mathrm{~mJ} \cdot \mathrm{cm}^{-2}$. As a consequence of plasma pre-treatment globular formations (Figure 1) appear. These surface fragments are connected with the ablation of amorphous phase that is typically higher than that of crystalline phase [11]. The applied laser exposure causes at lower laser pulses only a minor change in the surface roughness and morphology. Rather different situation was achieved for laser exposure with 6000 pulses. The plasma pre-treatment combined with consecutive laser exposure ( $9 \mathrm{~mJ}, 6000$ pulses) causes a sharp increase of surface roughness up to roughness $R_{\mathrm{a}}=25.7 \mathrm{~nm}$. The structure formation is connected to local surface melting caused by interaction of exposed polymer with laser. The microcrystalline regions of polymer bulk (crystallinity 60-70\%, according to Goodfellow Ltd.) may react with the incoming polarized laser beam which leads to surface melting, which causes consequent recrystallization. This phenomena together with strong 

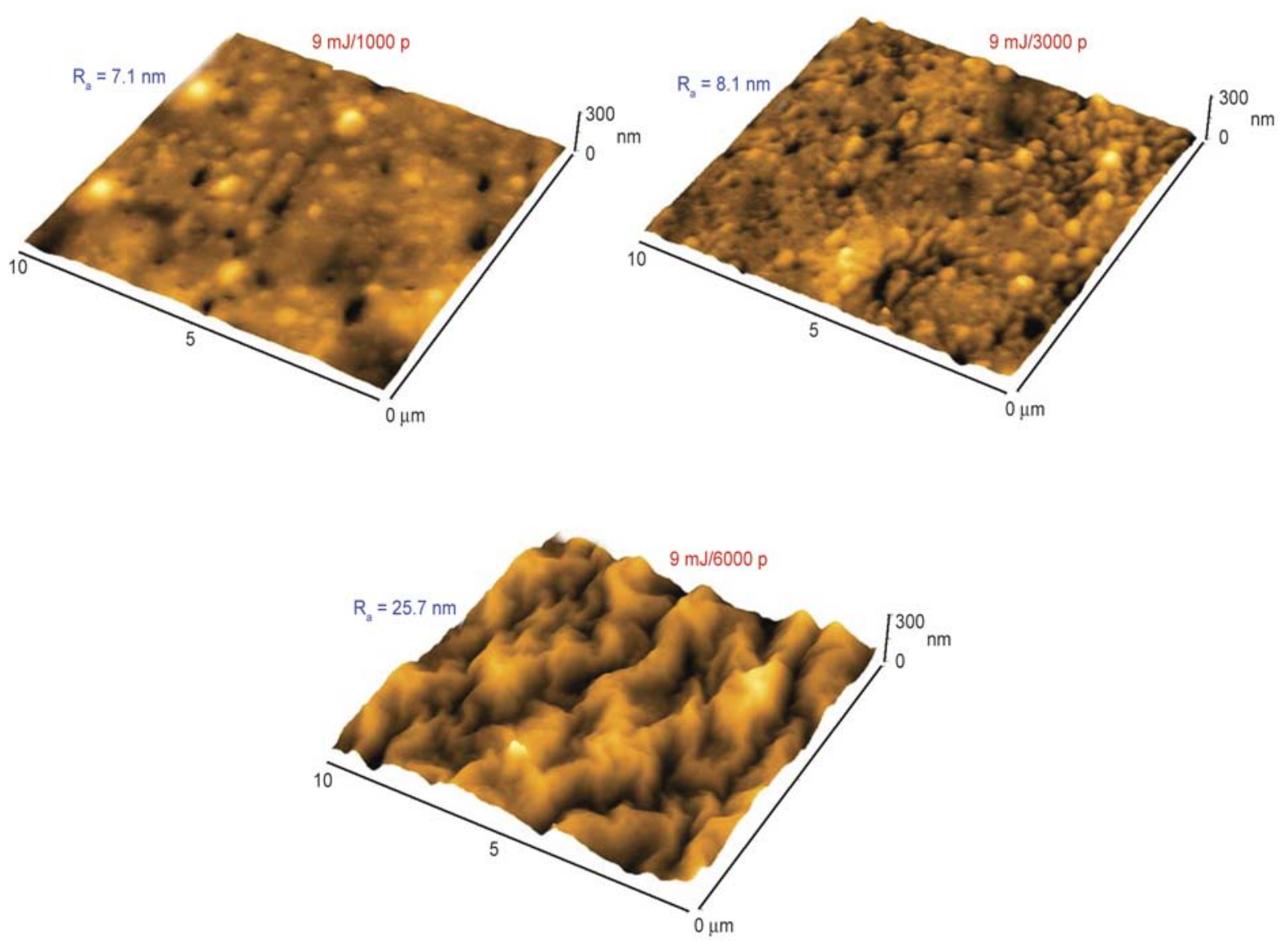

Figure 4. The surface morphology of plasma pre-treated PLLA and consequently exposed with laser beam with $9 \mathrm{~mJ} \mathrm{~cm}^{-2}$ and different number of pulses $(1000,3000$ and $6000 \mathrm{p}) . R_{\mathrm{a}}$ represents arithmetic mean roughness in $\mathrm{nm}$.

ablation process, when up to $1.5 \mu \mathrm{m}$ of PLLA could be removed induces a highly rough surface, applicable consequently e.g. as a scaffold for cell adhesion and proliferation improvement.

\subsection{Preparation of flat surface}

The effect of increase of surface roughness with increasing number of laser pulses can be observed up to a laser fluence of $20 \mathrm{~mJ} \cdot \mathrm{cm}^{-2}$. The reason for the increase of plasma pre-treated PLLA surface roughness (e.g. for $9 \mathrm{~mJ} \cdot \mathrm{cm}^{-2}$ ) is the ablation (polymer removal) connected with local heating and melting of laser exposed surface. The ratio of amorphous and crystalline phase (set by the plasma pretreatment, crystalline structures are revealed) is also strongly affected by the increase of laser fluence and polymer removal. The highest laser fluence $\left(30 \mathrm{~mJ} \cdot \mathrm{cm}^{-2}\right)$, on the contrary, causes probably such pronounced polymer ablation, that local melting prevails combined with consequent recrystallization. Therefore the opposite effect takes place and the roughness is reduced, as it is obvious in Figure 5 . The spherulitic structures exposed by plasma pre-treatment diminishes with increasing number of laser pulses (fluence $30 \mathrm{~mJ} \cdot \mathrm{cm}^{-2}$ ) and the surface roughness being strongly lowered. The dramatic surface roughness changes are visible in Figure 6. As it is evident from Figures 5 and 6, application of plasma pretreatment strongly influences the latter effect of laser exposure. If a lower laser fluence $\left(9 \mathrm{~mJ} \cdot \mathrm{cm}^{-2}\right)$ is applied, it leads to a strong amplification of surface roughness of PLLA. Higher laser fluence $\left(30 \mathrm{~mJ} \cdot \mathrm{cm}^{-2}\right)$ in combination with plasma pre-treatment has an opposite effect. This observation can find an excellent applications e.g. in tissue engineering [19], where the knowledge of both surface contact angle (wettability) and surface morphology and roughness is important for applicable scaffold construction.

\subsection{Optical properties}

The UV-VIS absorption spectra of laser exposed PLLA with 9 and $30 \mathrm{~mJ} \cdot \mathrm{cm}^{-2}$ by different number of laser pulses is introduced in Figure 7a. The same set of samples with plasma pre-treatment is introduced in Figure 7b. It is evident, that both laser flu- 

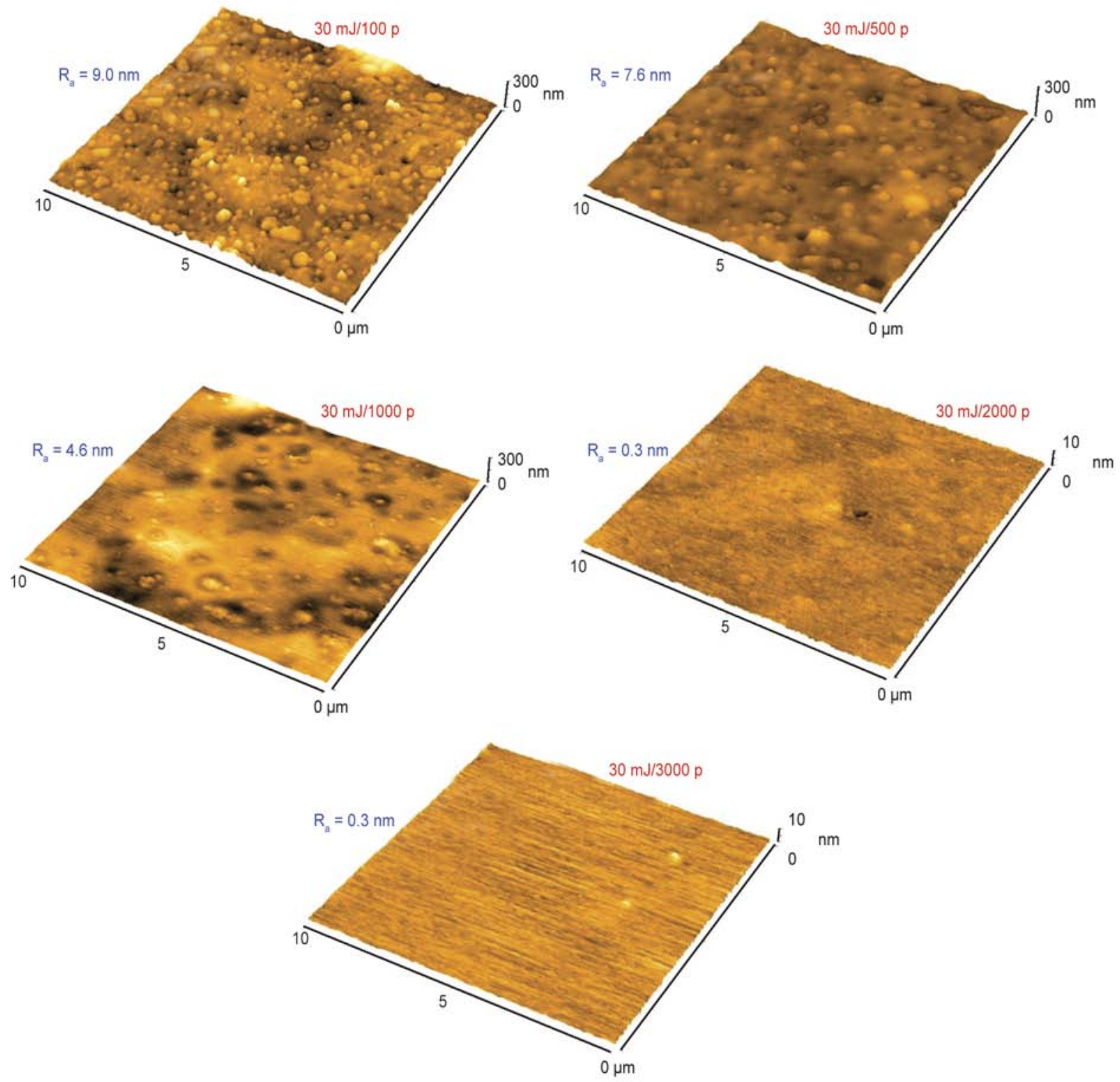

Figure 5. The surface morphology of plasma pre-treated PLLA and consequently exposed with laser beam with $30 \mathrm{~mJ} \mathrm{~cm}{ }^{-2}$ and different number of pulses $(100,500,1000,3000$ and $6000 \mathrm{p}) . R_{\mathrm{a}}$ represents arithmetic mean roughness in $\mathrm{nm}$.

ence and plasma pre-treatment with consequent laser exposure lead under certain conditions to surface resonance peak occurrence. The optical properties of interacting conjugated systems have often been discussed in the framework of molecular exciton theories based on (transition) dipole-dipole interaction models [20]. As it is obvious from Figure $7 \mathrm{a}$, consequent laser exposure significantly influences UV absorption. The slight effect of surface plasmon resonance is observed for higher laser fluence (both 1000 and 6000 pulses). The diagonal shift of the absorbance curve corresponds to increasing both the double bonds concentration [21].

Surface plasmon resonance (SPR) can be described as a collective oscillation of electrons in a solid or liquid stimulated by incident light. The condition for the resonance appearance is established when the frequency of light photons matches the frequency of surface electrons oscillating against the restoring force of positive nuclei. This effect when occurs in nanometer-sized structures is called localized surface plasmon resonance (LSPR). SPR reflectivity measurements can be used to detect molecular adsorption, such as polymers, DNA or proteins, molecular interaction studies [22]. The shift of the curves in extinction spectra can be explained by the coupling of the electromagnetic field between surface plasmons excited in gold nanoparticles of different density and size. 


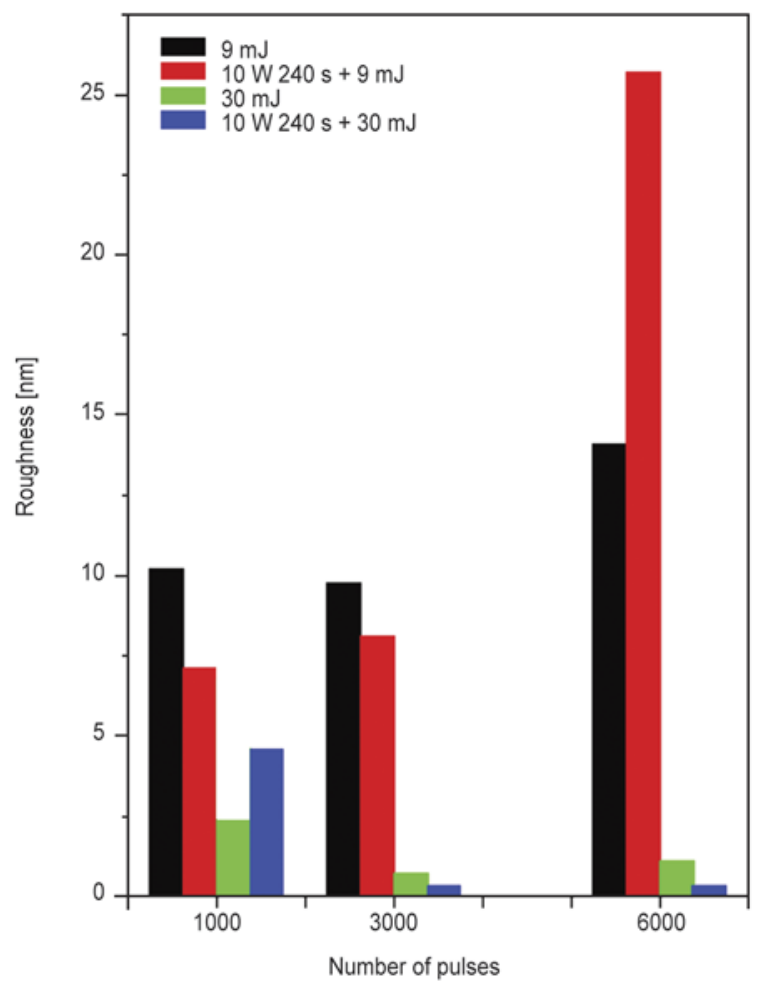

Figure 6. Surface roughness of samples of laser exposed PLLA or plasma pre-treated PLLA (10 W, $240 \mathrm{~s})$ and consequently exposed with laser ( 9 and $30 \mathrm{~mJ} \mathrm{~cm}{ }^{-2}$ ) with different number of pulses $(1000,3000$ and 6000)

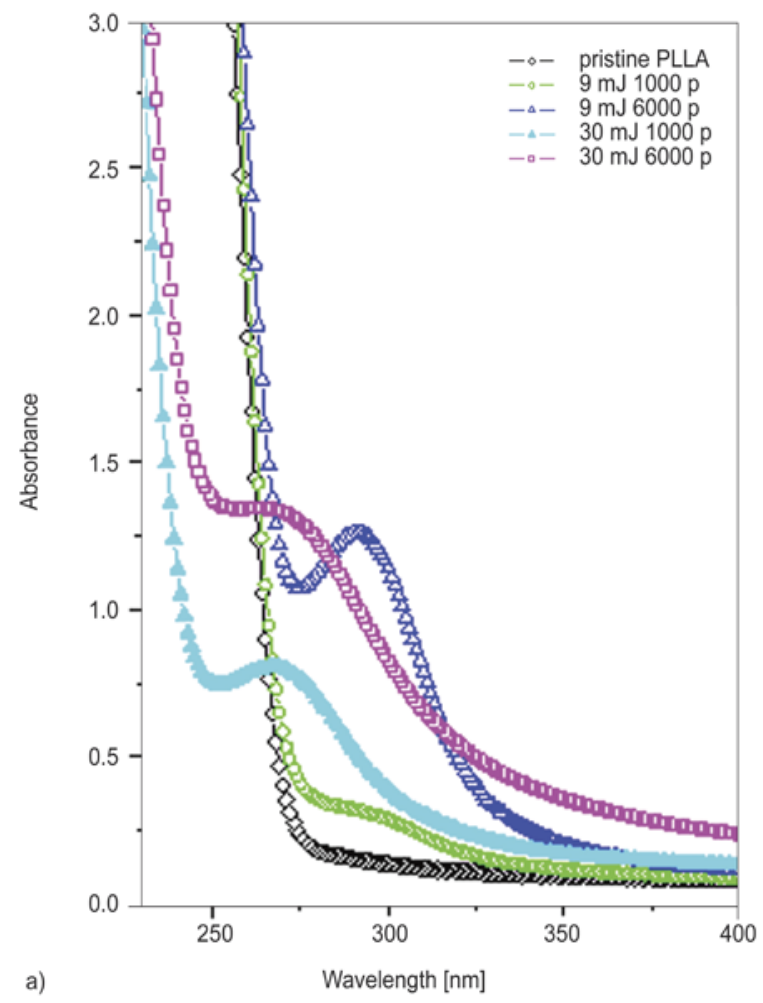

Rather different situation was observed for samples exposed with lower laser fluence, but number of pulses 6000. The strong peak of surface plasmon resonance was observed at a position of approx. $295 \mathrm{~nm}$, which indicated nanostructures formation on the PLLA laser exposed foil. The phenomenon of plasmon resonance probably arises from structural changes due to annealing while a PLLA surface is exposed to laser fluence. Both the shape and dimension of nanostructure can significantly influence the shape and position of surface plasmon peak [23]. The shift of the peak is connected with the nanoparticle dimension changes or the agglomeration effects. The shifts of the optical-absorption peak were also observed during the reduction of gold-sulfide particles to gold particles [24]. It was previously found, that by controlling the initial size of the gold-sulfide particles, the resonance shift can be correlated with a theoretical model that includes both quantum confinement and the resonance effects (the so-called surface-plasmon resonance) [24]. Ultra smooth surfaces from template-stripping procedures can be also used for periodic structures preparation [25], which can induce effects of surface-plasmon resonance.

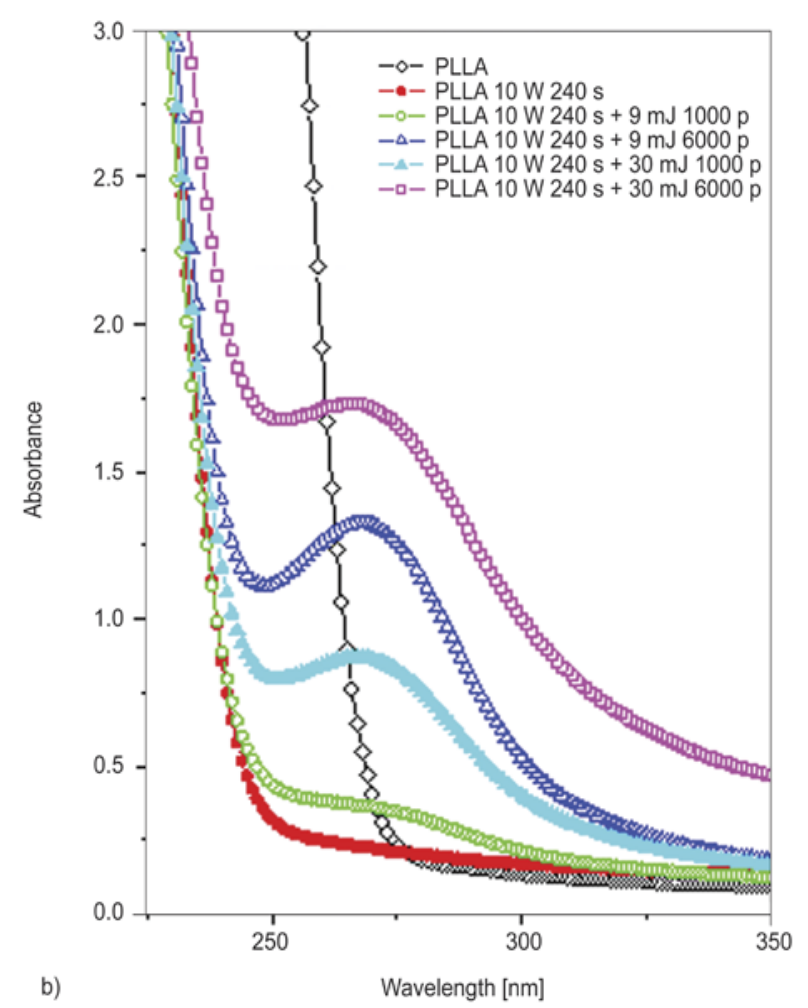

Figure 7. UV-Vis spectra of samples exposed with laser fluence 9 and $30 \mathrm{~mJ} \mathrm{~cm}^{-2}$ (1000 and 6000 pulses) (a); the same samples with plasma pre-treatment $(10 \mathrm{~W} 240 \mathrm{~s})(\mathrm{b})$. The spectra for pristine PLLA (a) and plasma pre-treated PLLA (10 W, $240 \mathrm{~s})(\mathrm{b})$ is introduced for comparison. 
The behavior of laser exposed foils with plasma pre-treatment is rather different. The peak of plasmon resonance can be found for the laser exposed samples at the constant position of approx. $270 \mathrm{~nm}$. With increasing the laser fluence and number of laser pulses only the amplification of the peak is apparent, which indicates increasing amount of nanostructures on the modified foils. The absolute value of the absorbance is higher with increasing laser fluence and number of pulses, which is probably caused by the changes in structure morphology, density and size of nanoparticles in the modified surface.

\section{Conclusions}

A method for preparation of biopolymer surface of high/smaller roughness has been introduced. Plasma pre-treatment of PLLA surface leads to the formation of pits consisting of crystalline phase with mild increase of surface roughness. The combination of plasma pre-treatment with consequent laser exposure leads to an extreme increase of PLLA surface roughness up to $26 \mathrm{~nm}$ with appearance of lamellar structures. The exposure of plasma pretreated surface by laser induces the ablation of PLLA surface. The ablation loss depends strongly on number of laser pulses and applied laser fluence. Under certain conditions a strong decrease of PLLA surface roughness was observed. Optical properties of plasma-pretreated PLLA with laser exposure exhibited plasmon surface resonance effects are dependent on laser fluence, which indicated nanostructures formation in the biopolymer surface.

\section{Acknowledgements}

This work was supported by the GACR under project 1306609S and by financial support from specific university research (MSMT No 20/2013).

\section{References}

[1] Tian H., Tang Z., Zhuang X., Chen X., Jing X.: Biodegradable synthetic polymers: Preparation, functionalization and biomedical application. Progress in Polymer Science, 37, 237-280 (2011).

DOI: $10.1016 /$ j.progpolymsci.2011.06.004

[2] Nair L. S., Laurencin C. T.: Biodegradable polymers as biomaterials. Progress in Polymer Science, 32, 762798 (2007).

DOI: 10.1016/j.progpolymsci.2007.05.017
[3] Hsu S-T., Tan H., Yao L.: Effect of excimer laser irradiation on crystallinity and chemical bonding of biodegradable polymer. Polymer Degradation and Stability, 97, 88-97 (2012).

DOI: $10.1016 /$ j.polymdegradstab.2011.10.006

[4] Gunatillake P., Mayadunne R., Adhikari R.: Recent developments in biodegradable synthetic polymers. Biotechnology Annual Review, 12, 301-347 (2006).

DOI: 10.1016/S1387-2656(06)12009-8

[5] Synytsya A., Grafová M., Slepička P., Gedeon O., Synytsya A.: Modification of chitosan-methylcellulose composite films with meso-tetrakis(4-sulfonatophenyl)porphyrin. Biomacromolecules, 13, 489-498 (2012).

DOI: $10.1021 / \mathrm{bm} 2015366$

[6] Synytsya A., Synytsya A., Blafková P., Ederová J., Spěváček J., Slepička P., Král V., Volka K.: pH-controlled self-assembling of meso-tetrakis(4-sulfonatophenyl)porphyrin-chitosan complexes. Biomacromolecules, 10, 1067-1076 (2009).

DOI: $\underline{10.1021 / \mathrm{bm} 8011715}$

[7] Donoso M. G., Méndez-Vilas A., Bruque J. M., González-Martin M. L.: On the relationship between common amplitude surface roughness parameters and surface area: Implications for the study of cell-material interactions. International Biodeterioration and Biodegradation, 59, 245-251 (2007).

DOI: $10.1016 /$ j.ibiod.2006.09.011

[8] Slepička P., Chaloupka A., Sajdl P., Heitz J., Hnatowicz V., Švorčík V.: Angle dependent laser nanopatterning of poly(ethylene terephthalate) surfaces. Applied Surface Science, 257, 6021-6025 (2011).

DOI: 10.1016/j.apsusc.2011.01.107

[9] Slepičková Kasálková N., Slepička P., Kolská Z., Sajdl P., Bačáková L., Rimpelová S., Švorčík V.: Cell adhesion and proliferation on polyethylene grafted with $\mathrm{Au}$ nanoparticles. Nuclear Instruments and Methods in Physics Research Section B: Beam Interactions with Materials and Atoms, 272, 391-395 (2012).

DOI: 10.1016/j.nimb.2011.01.108

[10] Rytlewski P., Mróz W., Żenkiewicz M., Czwartos J., Budner B.: Laser induced surface modification of polylactide. Journal of Materials Processing Technology, 212, 1700-1704 (2012).

DOI: 10.1016/j.jmatprotec.2012.03.019

[11] Siegel J., Řezníčková A., Chaloupka A., Slepička P., Švorčík V.: Ablation and water etching of plasmatreated polymers. Radiation Effects and Defects in Solids, 163, 779-788 (2008). DOI: $10.1080 / 10420150801969654$

[12] Slepička P., Michaljaničová I., Sajdl P., Fitl P., Švorčík V.: Surface ablation of PLLA induced by $\mathrm{KrF}$ excimer laser. Applied Surface Science, in press (2013). DOI: 10.1016/j.apsusc.2013.06.127 
[13] Hsu S-T., Tan H., Yao Y. L.: Effect of excimer laser irradiation on crystallinity and chemical bonding of biodegradable polymer. Polymer Degradation and Stability, 97, 88-97 (2012).

DOI: $10.1016 /$ j.polymdegradstab.2011.10.006

[14] Slepička P., Michaljaničová I., Slepičková Kasálková N., Kolská Z., Rimpelová S., Ruml T., Švorčík V.: Poly-L-lactic acid modified by etching and grafting with gold nanoparticles. Journal of Materials Science 48, 5871-5879 (2013). DOI: $10.1007 / \mathrm{s} 10853-013-7383-9$

[15] Ročková-Hlaváčková K., Švorčík V., Bačáková L., Dvořánková B., Heitz J., Hnatowicz V.: Bio-compatibility of ion beam-modified and RGD-grafted polyethylene. Nuclear Instruments and Methods in Physics Research Section B: Beam Interactions with Materials and Atoms, 225, 275-282 (2004).

DOI: 10.1016/j.nimb.2004.05.004

[16] Řezníčková A., Chaloupka A., Heitz J., Kolská Z., Švorčík V.: Surface properties of polymers treated with $\mathrm{F}_{2}$ laser. Surface and Interface Analysis, 44, 296-300 (2012).

DOI: $10.1002 /$ sia.3801

[17] Chu P. K., Chen J. Y., Wang L. P., Huang N.: Plasmasurface modification of biomaterials. Materials Science and Engineering: R: Reports, 36, 143-206 (2002). DOI: 10.1016/S0927-796X(02)00004-9

[18] Kotál V., Švorčík V., Slepička P., Sajdl P., Bláhová O., Šutta P., Hnatowicz V.: Gold coating of Poly(ethylene terephthalate) modified by argon plasma. Plasma Processes and Polymers 4, 69-76 (2007).

DOI: 10.1002/ppap.200600069

[19] Goddard J. M., Hotchkiss J. H.: Polymer surface modification for the attachment of bioactive compounds. Progress in Polymer Science, 32, 698-725 (2007). DOI: $10.1016 /$ j.progpolymsci.2007.04.002
[20] Cornil J., Beljonne D., Calbert J-P., Bredas J-L.: Interchain interactions in organic $\pi$-conjugated materials: Impact on electronic structure, optical response, and charge transport. Advanced Materials, 13, 1053-1067 (2001).

DOI: 10.1002/1521-4095(200107)13:14<1053::AIDADMA1053>3.0.CO;2-7

[21] Švorčík V., Prošková K., Hnatowicz V., Rybka V.: Alanine grafting of ion-beam-modified polyethylene. Journal of Applied Polymer Science, 75, 1144-1148 (2000).

DOI: 10.1002/(SICI)1097-4628(20000228)75:9<1144 $\because$ AID-APP7>3.0.CO;2-3

[22] McDonnell J. M.: Surface plasmon resonance: towards an understanding of the mechanisms of biological molecular recognition. Current Opinion in Chemical Biology, 5, 572-577 (2001).

[23] Amendola V., Bakr O. M., Stellacci F.: A study of the surface plasmon resonance of silver nanoparticles by the discrete dipole approximation method: Effect of shape, size, structure, and assembly. Plasmonics, 5, 8597 (2010).

DOI: $10.1007 / \mathrm{s} 11468-009-9120-4$

[24] Zhou H. S., Honma I., Komiyama H., Haus J. W.: Controlled synthesis and quantum-size effect in goldcoated nanoparticles. Physical Review B, 50, 1205212056 (1994). DOI: 10.1103/PhysRevB.50.12052

[25] Vogel N., Zieleniecki J., Köper I.: As flat as it gets: ultrasmooth surfaces from template-stripping procedures. Nanoscale, 4, 3820-3832 (2012). DOI: $10.1039 / \mathrm{C} 2 \mathrm{NR} 30434 \mathrm{~A}$ 